\title{
Cervical traction: a simple step ahead in the prevention of postpartum hemorrhage
}

\author{
Harshitha Naidu, Sujatha B. S.*, Muralidhar V. Pai
}

Department of Obstetrics and Gynecology, Kasturba Medical College, Manipal, Manipal Academy of Higher Education, Manipal, India

Received: 28 June 2019

Accepted: 03 July 2019

*Correspondence:

Dr. Sujatha B. S.,

E-mail: bssujata@gmail.com

Copyright: (c) the author(s), publisher and licensee Medip Academy. This is an open-access article distributed under the terms of the Creative Commons Attribution Non-Commercial License, which permits unrestricted non-commercial use, distribution, and reproduction in any medium, provided the original work is properly cited.

\begin{abstract}
Background: Postpartum hemorrhage is the most common preventable cause of maternal mortality in developing countries. The present study aimed to examine the impact of cervical traction technique in reducing the amount of postpartum blood loss and rate of PPH.

Methods: This was a case-control, pilot study conducted in a tertiary hospital between June 2017 to June 2018. A total of 200 singletons, low-risk pregnant females, undergoing normal vaginal delivery, were enrolled in this study. Subjects showing a high risk for PPH were excluded. Patients were randomized as case group ( $\mathrm{n}=100)$ and control group $(\mathrm{n}=100)$. The case group received sustained traction for 90 seconds to anterior and posterior lip of the cervix with active management of the third stage of labor, whereas the control group received routine active management of the third stage of labor. All subjects were followed up for 6 hours post-delivery. The amount of blood loss, hematocrit and hemoglobin post-delivery were compared between both groups.

Results: The mean blood loss $(\mathrm{ml})$, decrease in hemoglobin $(\mathrm{g} / \mathrm{L})$ and decrease in hematocrit post-delivery in cases were significantly low compared to controls $(207 \pm 37.6$ versus $340 \pm 49, \mathrm{P}<0.01),(0.78 \pm 0.2$ versus $1.4 \pm 0.3, \mathrm{P}=0.03)$ and $(1.7 \pm 0.2$ versus $3.5 \pm 0.2, \mathrm{P}<0.01)$. PPH occurred in 7 of $200(3.5 \%)$ patients. The difference in the number of PPH was not significant $(5 / 100 ; 5 \%$ versus $2 / 100 ; 2 \% \mathrm{P}=0.2)$. There were no complications reported due to cervical traction.

Conclusions: Cervical traction is a simple and safe maneuver to reduce the amount of postpartum blood loss. Larger $\mathrm{RCT}$ is recommended to investigate the reduction in $\mathrm{PPH}$ rate.
\end{abstract}

Keywords: Cervical traction, Blood loss, Maneuver, Maternal mortality, Postpartum hemorrhage, Vaginal delivery

\section{INTRODUCTION}

Postpartum hemorrhage (PPH) is excessive bleeding after child delivery. In general, vaginal delivery is associated with approximately $500 \mathrm{ml}$ of blood loss, while cesarean delivery involves blood loss of approximately $100 \mathrm{ml}$. $\mathrm{PPH}$ is associated with blood loss more than the abovementioned normal levels, blood loss that can cause hypovolemia, a decrease in hematocrit level by $10 \%$, and/or transfusion of blood products. Some of the associated risk factors include multiple pregnancies, placental abruption, placental previa, and over distended uterus.

According to the WHO report, about 14 million women worldwide suffer from PPH every year. ${ }^{1}$ The mortality incidence due to PPH is higher in low- and middleincome countries (approximately 99\%) compared to the industrialized countries (approximately 1\%). ${ }^{2}$ In developing countries, this maternal mortality risk is 1 in 
1000 deliveries and is steadily increasing. ${ }^{3}$ In India, PPHcaused maternal mortality was $30 \%$ in 1998 and has increased to $38 \%$ in $2003 .{ }^{4}$

Several factors contribute to PPH such as lack of adequate resources, anemia, lack of access to health care, poor management of the third stage of labor, and delays in transfer to the hospital. The main causes of PPH include uterine atony (inadequate uterine contraction) observed in $50 \%$ cases, uterine rupture, genital tract trauma (vaginal or cervical lacerations), retained placental tissue, or maternal bleeding disorders. ${ }^{4}$

Several methods have been proposed for decreasing the rate of $\mathrm{PPH}$. The WHO recommends "active management of the third stage of labour" (AMTSL) for reducing the incidence of $\mathrm{PPH}$ and maternal mortality. This involves a combination of pharmacologic and nonpharmacologic steps. It recommends prophylactic administration of uterotonic medicines such as oxytocin before the delivery of the placenta. It also includes controlled cord traction of the umbilical cord and late cord clamping. The AMTSL has been proved to reduce PPH effectively; however, 3-16.5\% women still suffer from $\mathrm{PPH}$ and require treatment. ${ }^{5}$

The rate of PPH and associated mortality in developing countries and increasing incidence of $\mathrm{PPH}$ in the developed countries indicate the requirement of simpler, non-expensive methods suitable for low-resource settings. Amr $\mathrm{H}$ et al, evaluated and reported the effectiveness of a new non-pharmacologic, less expensive maneuver applying sustained cervical traction to prevent $\mathrm{PPH} .{ }^{5}$ The use of ovum forceps to perform sustained traction to the anterior and posterior lips of the cervix so as to reach the vaginal introitus for about 90 seconds results in reduced blood loss and reduced incidence of uterine atony.

Objective of this study was to examine the impact of cervical traction in reducing the $\mathrm{PPH}$ rate and the amount of postpartum blood loss.

\section{METHODS}

This was a prospective, case-control, pilot study conducted at a tertiary care hospital from July 2017- June 2018. Two-hundred pregnant women who had uncomplicated vaginal delivery at our hospital during the study period were included in our study. Before enrollment in the study, the participants were explained the aim of the present study and informed consent was obtained. This study was approved by the Institute Ethics Committee (IEC 647/2017).

Exclusion criteria were ante-partum hemorrhage, placenta previa, pregnancy-induced hypertension or preeclampsia, diabetes, severe anemia $(\mathrm{HB}<8 \mathrm{mg} / \mathrm{dl})$, history of postpartum hemorrhage, twins pregnancy, and fetal macrosomia ( $>4 \mathrm{~kg}$ baby). Also, women with pre-existing maternal hemorrhagic conditions were excluded.

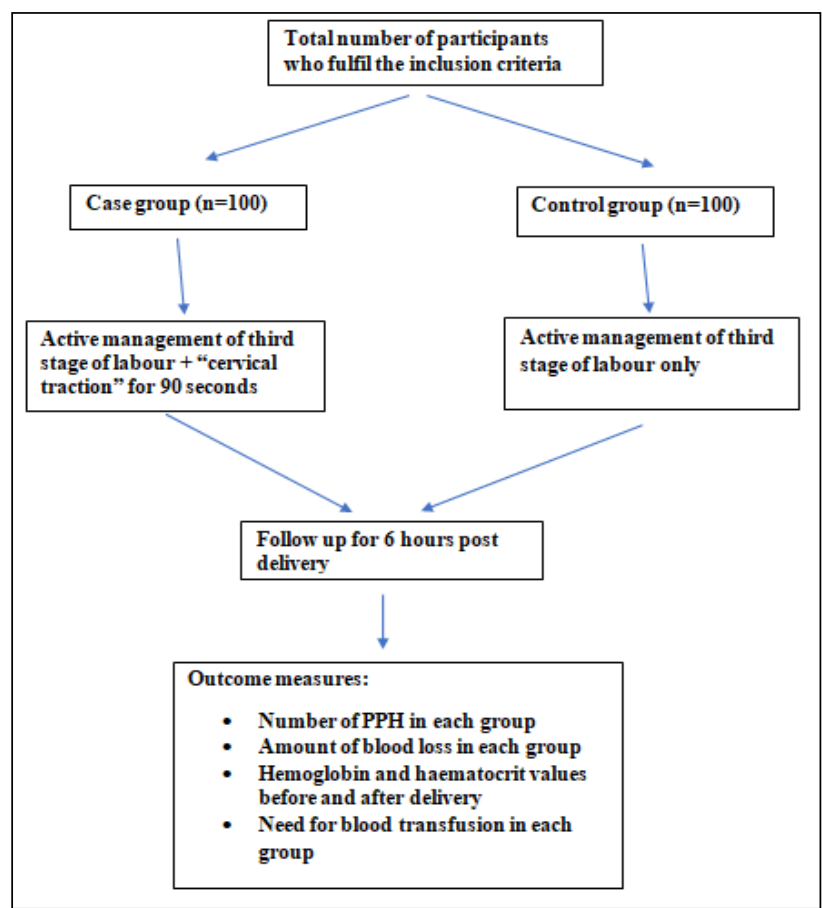

Figure 4: Flow chart of the study methodology.

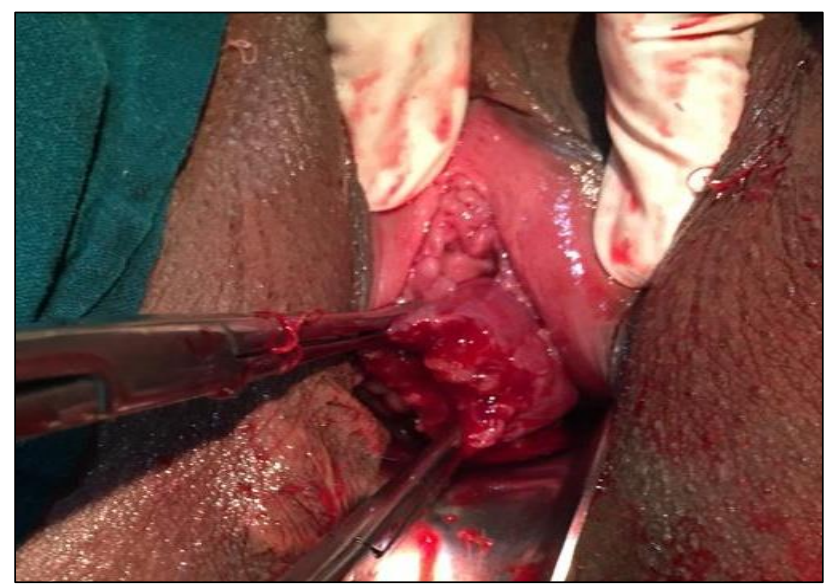

Figure 2: Sustained cervical traction (Amr's maneuver).

Figure 1 shows the methodology of the present study. A detailed medical history (obstetric, medical, and surgical) was obtained from all the participants. A complete general examination and obstetrical examination were performed. All participants were carefully observed for the time of placental delivery. Then, the participants were put into case group and control group to avoid bias. In the cases group, sustained cervical traction was given with sponge holding forceps to anterior and posterior lip of the cervix for 90 seconds, as shown in Figure 2 along with AMTSL. In the control group, only AMTSL was done. All the participants were followed up for 6 hours postdelivery. 


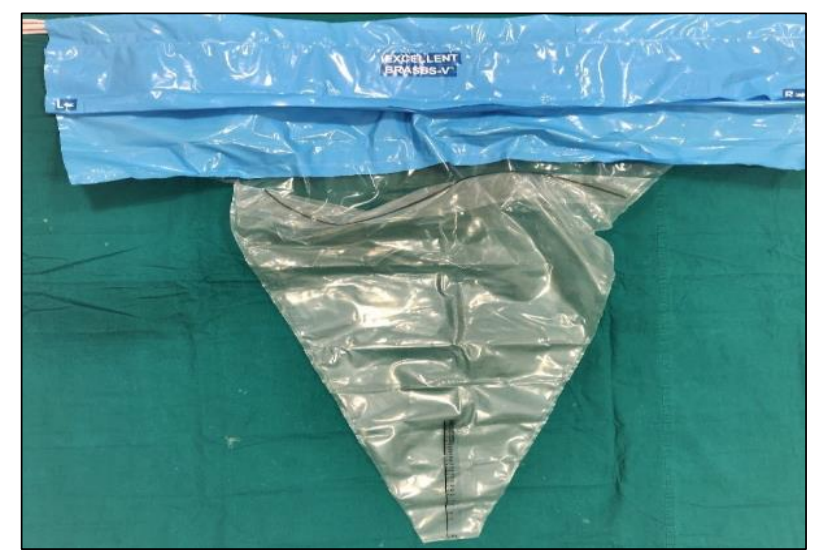

Figure 3: BRASS-V drape, used to estimate blood loss.

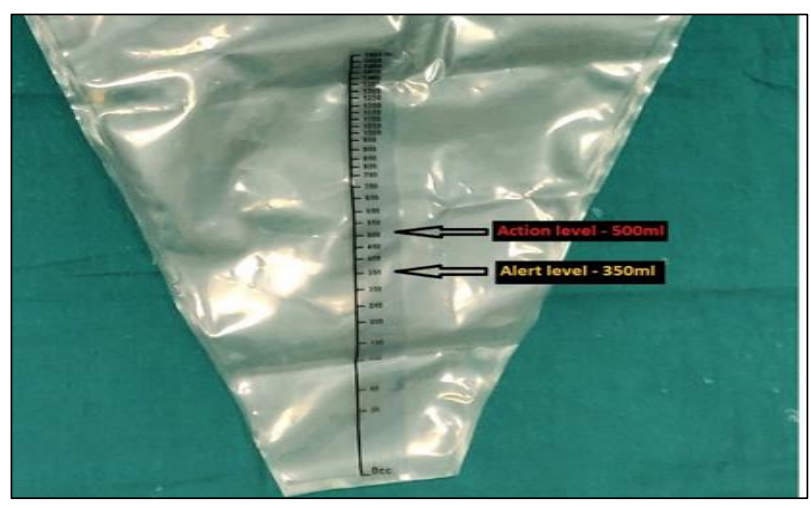

Figure 4: BRASS-V drape, showing alert level and action levels.

The amount of blood loss was determined by Brass- $\mathrm{V}$ drape (Figures 3 and 4), which was put under the buttocks of a woman soon after the delivery of the placenta. The rate of PPH, pre-and post-hemoglobin and hematocrit levels, and the number of patients requiring blood transfusion were assessed in each group. All participants were followed up post-delivery for any issues related to labor.

At our institute, we practice AMTSL for all vaginal deliveries. This includes-

- 10 units of IM oxytocin after delivery of anterior shoulder

- Uterine massage

- Controlled cord traction.

In our study, PPH is defined as the loss of blood more than $500 \mathrm{ml}$ or any amount of bleeding that causes hemodynamic instability. We routinely check hemoglobin and hematocrit levels in the third trimester and 6 hours post-delivery.

\section{Statistical analysis}

All statistical analyses were conducted via the SPSS software (version 20.0, SSPS Inc, Chicago, IL, USA) with a significance level of $95 \%$. Data for continuous variables were presented as mean \pm SD and compared using Student's t-test, while those for categorical variables were presented as percentages and frequency and compared using Pearson Chi-square or Phi test. Statistical significance was considered at $\mathrm{p}<0.05$.

\section{RESULTS}

Two-hundred participants were evaluated to assess the effectiveness of sustained cervical traction in preventing PPH. There were 100 participants in each case and control groups. Both the groups were compared for demographic and clinical parameters. No difference was noted between the two groups in terms of basic demographic characteristics such as age, BMI, and gestational age, thereby indicating that the two groups were comparable (Table 1).

Table 1: Demographic and clinical characteristics of study population.

\begin{tabular}{|c|c|c|c|}
\hline Characteristics & $\begin{array}{l}\text { Cases } \\
(n=100)\end{array}$ & $\begin{array}{l}\text { Controls } \\
(n=100)\end{array}$ & $\begin{array}{l}\mathbf{P} \\
\text { value }\end{array}$ \\
\hline Age (years) & $26.5 \pm 3.1$ & $26.9 \pm 4.8$ & 0.418 \\
\hline \multicolumn{4}{|l|}{ Parity } \\
\hline Nulliparous & 67 & 66 & \multirow[b]{2}{*}{0.881} \\
\hline Multipara & 33 & 34 & \\
\hline $\mathrm{BMI}^{*}\left(\mathrm{~kg} / \mathrm{m}^{2}\right)$ & $24.5 \pm 3.6$ & $23.9 \pm 3.6$ & 0.256 \\
\hline \multicolumn{4}{|c|}{ Gestational age (weeks) } \\
\hline Term & 95 & 96 & \multirow[b]{2}{*}{0.756} \\
\hline Preterm & 5 & 4 & \\
\hline $\begin{array}{l}\text { Systolic BP (mm } \\
\mathrm{Hg})\end{array}$ & $123 \pm 11.3$ & $121 \pm 11.8$ & 0.348 \\
\hline $\begin{array}{l}\text { Diastolic BP (mm } \\
\mathrm{Hg})\end{array}$ & $68 \pm 13.4$ & $70 \pm 12.2$ & 0.255 \\
\hline Hemoglobin $(\mathrm{g} / \mathrm{l})$ & $12.0 \pm 1.1$ & $12.0 \pm 1.17$ & 0.853 \\
\hline \multicolumn{4}{|c|}{ Anemia $(\mathrm{Hb}=<10 \mathrm{~g} / \mathrm{l})$} \\
\hline Mild anemia & 4 & 4 & \multirow[b]{2}{*}{1.0} \\
\hline No anemia & 96 & 96 & \\
\hline \multicolumn{4}{|l|}{ Vaginal delivery } \\
\hline with episiotomy & 92 & 95 & \multirow[b]{2}{*}{0.390} \\
\hline without episiotomy & 8 & 5 & \\
\hline \multicolumn{4}{|l|}{ Vaginal tears } \\
\hline Present & 1 & 2 & \multirow[b]{2}{*}{0.561} \\
\hline Absent & 99 & 98 & \\
\hline \multicolumn{4}{|c|}{ Birth weight (grams) } \\
\hline $\begin{array}{l}\text { Amount of blood } \\
\text { loss (ml) }\end{array}$ & $207 \pm 37.6$ & $340 \pm 49$ & $<0.01$ \\
\hline $\begin{array}{l}\text { Number of } \mathrm{PPH} \\
\text { cases }\end{array}$ & 2 & 5 & 0.248 \\
\hline $\begin{array}{l}\begin{array}{l}\text { Number of cases } \\
\text { received } \\
\text { transfusion }\end{array} \\
\text { blood }\end{array}$ & 1 & 2 & 0.1 \\
\hline
\end{tabular}

Data is represented as numbers, $\%$, mean $\pm \mathrm{SD}$, *BMI=body mass index, $\mathrm{BP}=$ blood pressure, $\mathrm{Hb}=$ hemoglobin, $\mathrm{PPH}=$ postpartum hemorrhage. 
Table 2: Descriptive statistics of pre-post hemoglobin and hematocrit values among cases and controls.

\begin{tabular}{|c|c|c|c|c|c|c|}
\hline \multirow[t]{2}{*}{ Parameter } & \multicolumn{2}{|l|}{ Cases $n=100$} & \multicolumn{2}{|l|}{ Controls ( $\mathrm{n}=100$ ) } & \multirow[t]{2}{*}{ t- value } & \multirow[t]{2}{*}{ P value } \\
\hline & $\begin{array}{l}\text { Pre-delivery Hb } \\
(\text { Mean } \pm \text { SD })\end{array}$ & $\begin{array}{l}\text { Post-delivery } \\
\text { Hb (Mean } \pm \text { SD })\end{array}$ & $\begin{array}{l}\text { Pre-delivery Hb } \\
(\text { Mean } \pm \text { SD })\end{array}$ & $\begin{array}{l}\text { Post-delivery } \\
\text { Hb (Mean } \pm \text { SD })\end{array}$ & & \\
\hline Hemoglobin $(\mathrm{Hb})(\mathrm{g} / \mathrm{l})$ & $12.05 \pm 1.12$ & $11.61 \pm 1.08^{*}$ & $12.5 \pm 1.17$ & $10.59 \pm 1.12 *$ & 4.83 & $<0.01 *$ \\
\hline Hematocrit value & $35.85 \pm 2.9$ & $34.08 \pm 3.45^{¥}$ & $35.07 \pm 3.8$ & $31.5 \pm 3.98^{¥}$ & 6.45 & $<0.01^{¥}$ \\
\hline Fall in hemoglobin & $0.44 \pm 1.04$ & & $1.4 \pm 1.39$ & & 5.67 & $<0.01$ \\
\hline Fall in hematocrit & $1.7 \pm 0.2$ & & $3.5 \pm 0.2$ & & 4.40 & $<0.01$ \\
\hline
\end{tabular}

The case group showed significant differences in the following variables: mean blood loss (Figure 5), decrease in hematocrit and decrease in hemoglobin levels postdelivery (Table 2). There were 7 cases of PPH ( 2 in case group and 5 in control group), which were not statistically significant. Only 1 participant in the case group received blood transfusion compared to 2 participants in the control group.

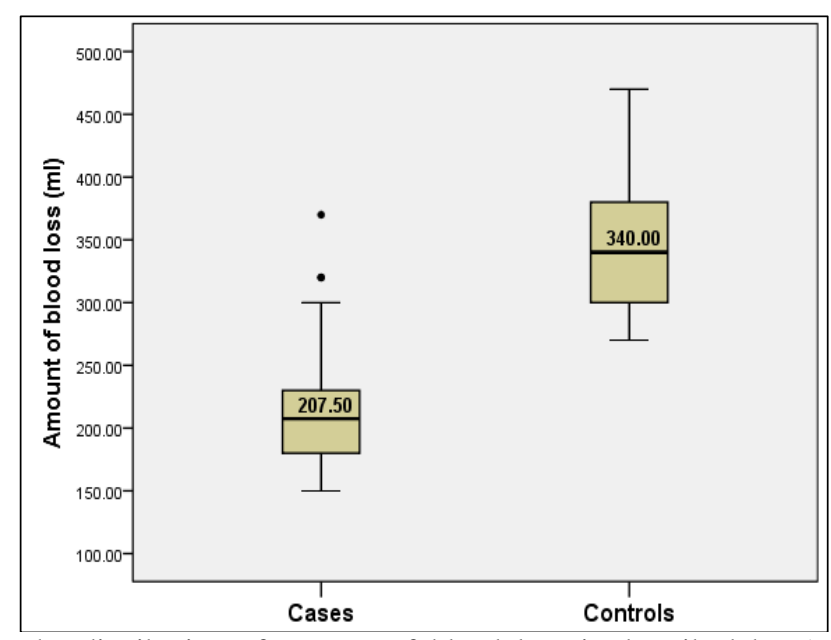

The distribution of amount of blood loss is described by 5number summary statistics. Observations excluded in the whiskers are represented as dots.

Figure 5: Boxplot diagram to compare the amount of blood loss among cases and controls.

\section{DISCUSSION}

Amr $\mathrm{H}$ et al, conducted a similar study in Egypt on 400 participants and showed reduced amount of blood loss and reduced incidence of $\mathrm{PPH}^{6}$ Our results were also similar to the results of a study conducted in India that reported a decrease in mean blood loss with the use of cervical traction method. ${ }^{7}$ Along with AMTSL, the cervical traction has significantly reduced blood loss after delivery, but the difference in the incidence of PPH was insignificant in groups because of the small sample size. The reduction in total blood loss was significant in the case group. The consequent decreases in hemoglobin and hematocrit levels were also significant. This indicates that saving blood loss had a positive effect on the other important factors as well. It would have been interesting to include some other dependent factors in the study.

Apart from the smaller sample size, our study did not account for the effect of AMTSL. Both the groups received AMTSL as a routine practice at the hospital. So, the effects of the AMTSL and the new maneuver cannot be separated. This is reflected in the insignificant difference in the incidence rate of PPH in both groups. Hence, we suggest a three-arm RCT to compare the cervical traction maneuver, AMTSL and passive management of the third stage of labor. Thus, we can study whether this cervical traction maneuver can be incorporated as a mechanical method to reduce the rate of $\mathrm{PPH}$ in a low-resource setting.

Mortality risk due to PPH is much higher in low- and medium-income countries. Hence, the solution to combat the problem should be inexpensive so that the lowresource settings could easily incorporate it in their routine practice. Apart from being inexpensive, this sustained traction method is simple and easy to adopt in a routine as it does not require any special instruments/machines or training.

In the third stage of the labor, oxytocin is released in a continuous feedback cycle. This leads to contraction of uterus to deliver the baby and later on the placenta. The sustained traction maneuver used in the study might produce a similar effect as it persistently stimulates the stretch receptor of the cervix to release more oxytocin. Consequently, this oxytocin contracts the uterine muscle fibers, resulting in significantly reduced loss of blood after delivery of the placenta. The maneuver may also kink redundant uterine arteries, resulting in slow blood flows that facilitate the formation of clotting and thrombin. One of the limitations of the study was inadequacy in measuring accurate blood loss. The PPH is sudden and fatal; hence, the accurate assessment of blood loss is crucial to treat the condition. Visual method to assess the blood loss is subjective and needs special training for accurate results. Hence, the standardized method is preferred.

The study included cases only with vaginal deliveries as the sustained traction technique has applicability only in vaginal deliveries. However, for cesarean section 
deliveries where the risk of PPH is higher and more unpredictable, the technique does not have any applicability. In low-income, low-resource settings, the probability of having vaginal delivery is impacted by many factors. Hence, the requirement of a different maneuver to tackle the problem of $\mathrm{PPH}$ and associated mortality is apparent. This is a clear limitation of the cervical sustained traction method.

\section{CONCLUSION}

PPH remains the most important reason for maternal mortality in both developing and developed countries. Although high-resource settings have breakthroughs in the prevention and management of $\mathrm{PPH}$, the low-resource settings lack access to well-staffed and well-stocked facilities that can cater to emergency PPH. This newer maneuver might be a promising and lifesaving intervention in developing countries. But further clinical research is required to demonstrate its acceptability, efficacy, and sustainability/cost-effectiveness in preventing $\mathrm{PPH}$ before its large-scale introduction. AMR'S MANEUVER (sustained cervical traction) is a simple and safe method that reduces blood loss during the third stage of labor, thereby preventing PPH. However, further large randomized clinical trials to study the effectiveness of the method are recommended.

Funding: No funding sources Conflict of interest: None declared

Ethical approval: The study was approved by the Institutional Ethics Committee

\section{REFERENCES}

1. Trends in Maternal Mortality: 1990 to 2010. WHO, UNICEF, UNFPA, and The World Bank estimates. Geneva, WHO, 2012. Available at: http://whqlibdoc. who.int/publications/2012/9789241 503631_eng.pdf. Accessed on $1^{\text {st }}$ September 2012.

2. Haeri S, Dildy III GA. Maternal Mortality from Hemorrhage. Seminars Perinatol. 2012;36(1):48-55.

3. Knight M. Trends in postpartum hemorrhage in high resource countries: a review and recommendations from the International Postpartum Hemorrhage Collaborative Group. BMC Pregnancy Childbirth. 2009;9(1):55.

4. Postpartum hemorrhage, 2019. Available at: http://www.nhp.gov.in.

5. Priority medicines for Europe and the World "A Public Health Approach to Innovation", 2013. Available at: https://www.who.int/medicines/ areas/priority_medicines/BP6_16PPH.pdf.

6. Hamdy A. A new maneuver for prevention of postpartum haemorrhage. J Obstet Gynecol India. 2014;65(4):241-5.

7. Preethima T, Jayashree V, Latha K. A study of sustained cervical traction in the prevention of post partum hemorrhage. Int $\mathbf{J}$ Modern Res Rev. 2019;4(11):1368-71.

Cite this article as: Naidu H, Sujatha BS, Pai MV. 'Cervical traction': a simple step ahead in the prevention of postpartum hemorrhage. Int J Reprod Contracept Obstet Gynecol 2019;8:3174-8. 